\title{
Trastorno por déficit de atención e hiperactividad y su prevalencia en estudiantes de Medicina de Ia Universidad Autónoma de Aguascalientes
}

Cienfuegos-Meza J, Gaytán-Magaña JJ, ${ }^{*}$ Hermosillo-Pérez SN, ${ }^{*}$ Martínez-Sánchez AE,

Oropeza-Prieto A, ${ }^{*}$ Rodríguez-Mendoza RL, ${ }^{*}$ Rodríguez-Pérez $D,{ }^{*}$

Villalobos-Peña FJ, * García-Huízar MP, ${ }^{* *}$ Terrones-Saldívar MC ${ }^{* * *}$

\section{Resumen}

- El objetivo de este trabajo fue describir la prevalencia

- del trastorno de déficit de atención e hiperactividad en

- estudiantes de la carrera de Medicina de la Universi-

- dad Autónoma de Aguascalientes. Material y métodos:

- Se encuestaron estudiantes de los semestres primero,

- tercero, sexto, octavo y décimo de la carrera de Médico

- Cirujano de la Universidad Autónoma de Aguascalien-

- tes, mediante la Sección A de la Escala de Auto-Re-

- porte de Síntomas de TDAH en Adultos (ASRS-v1.1).

- Se tomaron las variables de edad, sexo y semestre. De

- acuerdo a la edad se clasificaron los siguientes grupos:

- Grupo I (I 8 años), Grupo II (19 años), Grupo III (20

- años), Grupo IV (2I años), Grupo V (22 años), Grupo

- VI (23 años) y Grupo VII (24 años). Resultados: Se en- cuestaron un total de 99 estudiantes, el promedio de edad fue de 20.5 años (Rango 18 a 24 años), 42.4\% mujeres $(n=42)$ y $57.6 \%$ hombres $(n=57)$. Se encontró a 28 estudiantes (28.2\%) con puntuación mayor a 4 en la sección A de la escala de evaluación. Dentro de este grupo, se obtuvo por género femenino (35.7\%, $n=10)$ y masculino (64.3\%, $n=18)$. La prevalencia de TDAH fue mayor en los estudiantes de los semestres más avanzados de la carrera de Médico Cirujano, 10 que nos sugiere la influencia del estrés sobre la prevalencia de este trastorno. LUXMÉDICA 7(20): LUXMÉDICA 7(20): $55-59$

Palabras clave: déficit de atención, hiperactividad, estudiantes de medicina.

* Estudiantes de la carrera de Medicina de la Universidad Autónoma de Aguascalientes

** Profesoras investigadoras del Centro de Ciencias de la Salud de la UAA

Fecha de recibido: 15 agosto 2011

Fecha de aceptación: 20 de febrero 2012

Correspondencia: Dra Ma del Pilar García Huízar, Psiquiatra, Departamento de Medicina del Centro de Ciencias de la Salud de la Universidad Autónoma de Aguascalientes. Avenida Aguascalientes \#940. Código postal 20131. Teléfono 9108436. Correo electrónico 


\section{Introducción}

El trastorno por déficit de atención con hiperactividad (TDAH), es una entidad clínica caracterizada por dificultad en el mantenimiento de la atención, que se acompaña en ocasiones de hiperactividad e impulsividad y que incide negativamente en el desempeño académico, cognoscitivo y social de quien lo padece. ${ }^{1}$ Durante años se pensó que era un trastorno que afectaba únicamente a la población infantil-juvenil. Sin embargo, en el último tercio del siglo pasado, se observó que los síntomas del TDAH no desaparecen al inicio de la vida adulta, sino que se mantienen en más del $50 \%$ de los casos. ${ }^{2}$ El DSM IV-TR establece un grupo de 18 criterios diagnósticos para TDAH, consistiendo en nueve síntomas relacionados con la falta de atención y nueve síntomas relacionados con la hiperactividad y/o impulsividad. Para poder diagnosticar el TDAH en un adulto es preciso 1) que el trastorno esté presente desde la infancia, como mínimo desde los 7 años; y 2) que persista una alteración clínicamente significativa o un deterioro en más de un área importante de su actividad (social, laboral, académico o familiar) ${ }^{3,4}$.

Aún se desconoce la fisiopatología del TDAH, pero se considera multifactorial, con influencias genéticas, ambientales y neurobiológicas. ${ }^{2,5} \mathrm{La}$ evidencia sugiere que se debe a un desorden prioritariamente poligénico, que involucra al menos 50 genes. ${ }^{6}$ La hipótesis principal está en relación a la disfunción del sistema dopaminérgico ${ }^{6}$, sin embargo, otras alteraciones morfológicas ${ }^{5}$ y del sistema serotoninérgico, así como múltiples genes, se encuentran relacionadas ${ }^{7}$.

En la comunidad científica, el valor más aceptado de la prevalencia global del TDAH en sus diversas formas, se sitúa entre el 3 y $7 \%$ en niños de edad escolar. ${ }^{6}$ En el caso de México se calcula que existen al menos $1,500,000$ niños con este problema. ${ }^{8}$ La prevalencia es más alta en niños que en niñas. Los estudios reflejan relaciones de 4:1 a 9:1 (H:M). ${ }^{9}$ Los datos de la prevalencia en la adolescencia y vida adulta son imprecisos. Contribuye a esa imprecisión el hecho de que la sintomatología del TDAH sigue un curso evolutivo y cambia en función de la edad. Estudios indican que del 50 al $80 \%$ persiste en la adolescencia y del 40 al $60 \%$ persiste en la edad adulta. ${ }^{2,5}$

En México se cuenta con pocos estudios que evalúen la prevalencia del TDAH en poblaciones de adultos, particularmente de estudiantes universitarios. ${ }^{10}$ El presente trabajo tiene como objetivo describir la prevalencia del TDAH en estudiantes de la carrera de Médico Cirujano de la Universidad Autónoma de Aguascalientes.

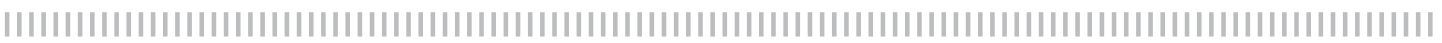

\section{Material y métodos}

El diseño del estudio fue descriptivo y transversal. Se encuestó a estudiantes de la carrera de Médico Cirujano de la Universidad Autónoma de Aguascalientes, tomando una muestra de estudiantes por grupo de los semestres primero, tercero, sexto, octavo y décimo. El cuestionario se aplicó durante el mes de noviembre de 2010. Se utilizó como instrumento de medición la Escala de Auto-Reporte de Síntomas de TDAH en 
Adultos (ASRS-v1.1), de la cual sólo se les pidió a los participantes que contestaran la sección $A$. De acuerdo a la escala, se tomó un valor de cuatro puntos o más para considerar la posibilidad de TDAH. De todos los participantes se obtuvo el consentimiento para la utilizar la información. Se tomaron en cuenta los siguientes variables: edad, sexo y semestre. De acuerdo a la edad se clasificaron los siguientes grupos: Grupo I (18 años), Grupo II (19 años), Grupo III (20 años), Grupo IV (21 años), Grupo V (22 años), Grupo VI (23 años) y Grupo VII (24 años). Se utilizó el programa Statistica v. 8.0 para el análisis estadístico, los resultados se muestran en medidas de tendencia central.

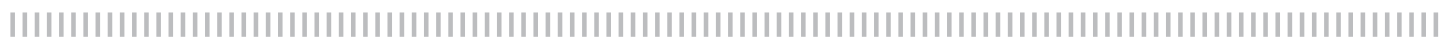

\section{Resultados}

Se encuestaron un total de 99 estudiantes, el promedio de edad fue de 20.5 años (Rango 18 a 24 años), $42.4 \%$ mujeres $(n=42)$ y $57.6 \%$ hombres $(n=57)$. Se detectaron 28 casos con puntuación mayor a 4 en la sección A de la escala de evaluación ASRS-v1.1, lo que representa una prevalencia de TDAH de el $28.2 \%$. Dentro de este grupo, se obtuvo, por género, menor porcentaje en el sexo femenino $(35.7 \%, \mathrm{n}=10)$ que en el masculino $(64.3 \%, \mathrm{n}=18)$.

La distribución de los 28 estudiantes con TDAH, por grupo de edad, fue de $7.1 \%(2 / 28)$ para el Grupo I; $7.1 \%$ (2/28) para el Grupo II; 14.3\% (4/28) para el Grupo III; 32.1\% (9/28) para el Grupo IV; 21.4\% (6/28) para el Grupo $\mathrm{V} ; 10.7 \%$ (3/28) para el Grupo VI y $7.1 \%$ (2/28) para el Grupo VII (Gráfico 1).

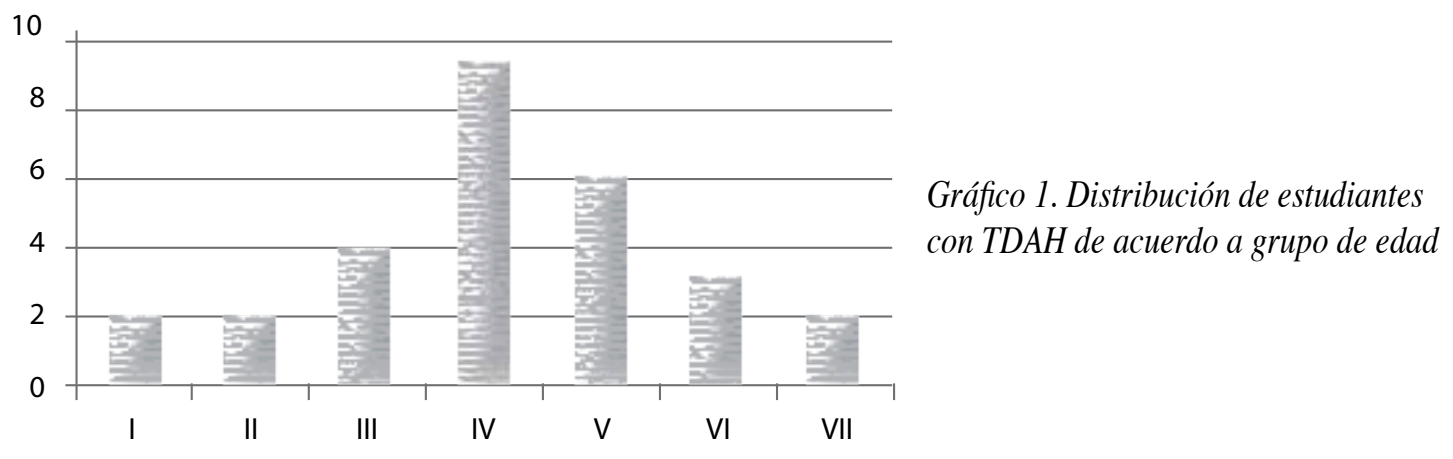

La distribución de los 28 estudiantes con TDAH, de acuerdo al semestre, fue la siguiente: en el primer semestre el $10.7 \%(3 / 28)$, en el tercer semestre el $3.6 \%(1 / 28)$, en el sexto semestre el $28.6 \%(8 / 28), 25 \%(7 / 28)$ para el octavo semestre y $32.1 \%(9 / 28)$ para el décimo semestre (Gráfico 2).

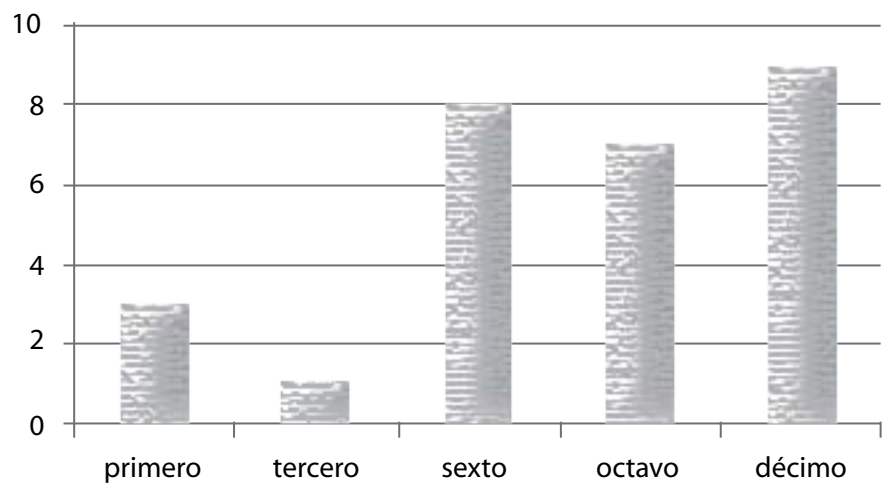

Gráfico 2. Distribución de estudiantes con TDAH de acuerdo al semestre que cursa, de la carrera de medicina. 


\section{Discusión}

Aproximadamente el $50 \%$ de los adolescentes con TDAH tienen dificultades sociales, académicas y emocionales, además de que manifiestan un pobre rendimiento escolar. ${ }^{11} \mathrm{El}$ diagnóstico de TDAH en estudiantes universitarios y adultos es controvertido y la aplicación de criterios del DSM IV ha sido cuestionada, ya que los síntomas que manifiestan son distintos a los de la infancia. ${ }^{10}$

En el presente estudio se determinó la prevalencia del TDAH en una población universitaria. Los resultados van de acuerdo al estándar aceptado de proporción de género, encontrándose una relación de 1.8:1 de hombres a mujeres. Se utilizó la Sección A de la Escala de Auto-Reporte de Síntomas de TDAH en Adultos (ASRS-V1.1), desarrollada por la Organización Mundial de la Salud (OMS) y el Grupo de Trabajo en Adultos con TDAH. Los contenidos del cuestionario son consistentes con los criterios diagnósticos del DSM IV, y la Sección A del mismo consiste en seis tópicos relacionados con los síntomas más predictivos del padecimiento.

En cuanto a la edad se encontró que la mayoría de los estudiantes con TDAH, en este estudio, tenían un promedio de 20.5 años, esto resultado es similar a lo reportado en estudios previos. En un estudio con 128 participantes con un promedio de edad de 19 años, se documentó que el 38\% cumplían los criterios diagnósticos para TDAH de acuerdo a las especificaciones del DSM-III-R, y el $72 \%$ presentaba como mínimo un tercio de los síntomas requeridos para el diagnóstico. ${ }^{12}$ Existen pocos estudios con las mismas características de población en México y Latinoamérica. ${ }^{1,6,10-18}$

Por otra parte, destaca en los resultados un patrón ascendente conforme se progresa en el nivel de estudios. En este trabajo, los grupos con resultados más altos en la escala de evaluación fueron aquellos en los últimos semestres de la carrera de Médico Cirujano. Está bien establecido la influencia del medio ambiente en el desarrollo del TDAH ${ }^{2,5-7}$, y en este caso, nos hace pensar en la influencia del estrés como desencadenante. En México se cuenta con pocos estudios que evalúen la prevalencia del TDAH en poblaciones estudiantiles de nivel superior, encontrándose en la literatura estudios que evalúan poblaciones de menor grado académico. ${ }^{10,}$ 13-15 El diagnóstico en este grupo de población suele ser más complejo, ya que en la población adolescente los síntomas suelen atenuarse a medida que avanzan en edad, hasta llegar a la edad adulta y, de este grupo, alrededor de uno de cada tres sujetos reúnen criterios diagnósticos completos del TDAH a la edad de 18 años. Además, algunos estudios se han enfocado en medir la especificidad de los parámetros de diagnóstico de TDAH de acuerdo al DSM-IV en estudiantes universitarios, encontrando que muchos de ellos que aparentemente reúnen las características necesarias para ser diagnosticados con TDAH, no tienen este trastorno. ${ }^{16}$ La variabilidad de los síntomas y el cambio en los subtipos del TDAH en la edad adulta es un factor importante. Se ha reportado que el subtipo combinado es mucho menos común, ya que los síntomas de éste probablemente sean un impedimento para que logren ingresar a la universidad. ${ }^{17}$

Una debilidad de nuestro estudio es el tamaño de la muestra, la cual fue de 99 estudiantes y sólo representa una parte de la población estudiantil total de la carrera de Medicina de la Universidad Autónoma de Aguascalientes. Sin embargo, no existen estudios en poblaciones similares en la región. Un punto importante es la relación de la edad y el semestre con la mayor prevalencia del TDAH en nuestro estudio, lo cual podría indicar una relación entre los niveles de estrés y el desarrollo del TDAH. Hacen falta más estudios para evaluar esta posibilidad. 


\section{Conclusiones}

En el presente estudio, la prevalencia de TDAH fue de $28.2 \%$, siendo de predominio en los estudiantes de los semestres más avanzados de la carrera de Médico Cirujano, lo que nos sugiere la influencia del estrés sobre la prevalencia de este trastorno.

Un informe claro de los síntomas de TDAH no siempre se obtiene a través de una sola fuente, por lo que se sugiere aplicar cuestionarios de tamizaje para detectar sintomatología de TDAH en estudiantes y los probables casos deben ser evaluados con un estudio clínico completo. ${ }^{10}$ Cuando se identifica el TDAH en preparatoria y en la universidad, es muy importante que el estudiante reciba atención especializada.

\section{Bibliografía}

1.- Vélez van Meerbeke, Alberto et. al. Prevalencia de trastorno por déficit de atención con hiperactividad en estudiantes de escuelas de Bogotá, Colombia Acta Neurol Colomb Vol. 24 No. 1 Marzo 2008

2.- Moss, Shannon B. Nair, Rajasree. Vallarino, Anthony. Wang, Scott. Attention Deficit/Hyperactivity Disorder in Adults. Prim Care Clin Office Pract 34 (2007) 445-473.

3.- Kooij et al. European consensus statement on diagnosis and treatment of adult ADHD: The European Network Adult ADHD. BMC Psychiatry 2010, 10:67.

4.- Capilla-González A. et. al. "Nuevas aportaciones a la neurobiología del trastorno por déficit de atención con hiperactividad desde la magnetoencefalografía" NEUROL 2005; 40 (Supl 1): S43-S47.

5.- Almeida Montes, LG, et. al. Alteraciones estructurales encefálicas en el trastorno por déficit de atención e hiperactividad: una actualización. Salud Mental 2009; 32:503-512.

6.- Barragán-Pérez, E. et. al. Primer consenso latinoamericano de trastorno por déficit de atención e hiperactividad. Bol Med Hosp Infant Mex (64), 2007.

7.- Faraone, Stephen V. Mick, Eric. Molecular Genetics of Attention Deficit Hyperactivity Disorder. Psychiatr Clin N Am 33 (2010) 159-180.

8.- Joffre-Velázquez VM, et. al. Trastorno por déficit de la atención e hiperactividad de la infancia a la vida adulta. Archivos en Medicina Familiar (2007) 9; 4: 176- 181.

9.- American Psychiatry Association. Diagnostic and Statistical Manual of Mental Disorders, DSM IV-TR. $4^{\circ}$ ed. American Psychiatric Association, Washington, DC, 2002.

10.- Ortiz León, S, y Medrano, ALJ. El trastorno por déficit de atención e hiperactividad en estudiantes universitarios. Rev Fac Med UNAM (2007) 50; 3 : 125-127.

11.- Menendez-Benavente I. Trastorno de deficit de atencion con hiperactividad: Clinica y Diagnostico en ninos y adolescentes. Psiquiatr Psicol. 2001; 4: 92-102.

12.- Spencer T, Biederman J, Wilens TE, Faraone SV. Adults with attention deficit hyperactivity disorder: a controversial diagnosis. J Clin Psychiatry 1998; 59: 59-68.

13.- Cruz Alcalá, LE et. al. Prevalencia del trastorno por déficit de atención e hiperactividad en escolares de Jalisco. Rev Mex Neuroci 2010; 11(1): 15-19.

14. Carreón Chavarría, BC et. al. Trastorno por déficit de atención e hiperactividad y el puntaje SAT en una preparatoria privada. AVANCES (2010); 4-9.

15.- Juárez-Velázquez, MC et. al. Diseño de un cuestionario de tamizaje para el trastorno por déficit de atención e hiperactividad en adolescentes. Enlaces académicos. 2009; Vol. 2, No. 1.

16.- Heiligenstein E, Guenther G, Levy A, Savino F, Fulwiller J. Psychological and academic functioning in college students with attention deficit hyperactivity disorder. Journal of American College Health 1999; 47: 181-5.

17. Du Paul G, Schaughency E, Weyandt L, Tripp G, Kiesner J, Ota K, Stanish H. Self report of ADHD symptoms in university students: Cross-gender and cross-national prevalence. Journal of Learning Disabilities 2001; 34: 370-380.

18. Cornejo JW, Osío O, Sánchez Y, Carrizosa J, Sánchez G, Grisales H, Castillo-Parra H, Holguín J. Prevalencia del trastorno por déficit de atención-hiperactividad en niños y adolescentes colombianos Rev Neurol 2005; 40 (12): 716-722 